Article

\title{
Postnatal Acetaminophen and Potential Risk of Autism Spectrum Disorder among Males
}

\author{
Seth S. Bittker ${ }^{1, * \mathbb{D}}$ and Kathleen R. Bell ${ }^{2}$ \\ 1 Ronin Institute, Montclair, NJ 07043, USA \\ 2 Ontario College of Teachers, Toronto, ON M5S 0A1, Canada; katieroberta@gmail.com \\ * Correspondence: seth.bittker@ronininstitute.org
}

Received: 27 October 2019; Accepted: 30 December 2019; Published: 1 January 2020

\begin{abstract}
Some evidence from the literature suggests that postnatal acetaminophen exposure may be associated with increased risk of autism spectrum disorder (ASD). Using a data set obtained from a previous study that was derived from an Internet-based survey among parents on 1515 children from the US, an adjusted odds ratio (aOR) and gender-specific aORs for doses of postnatal acetaminophen provided before age two were calculated against the outcome of ASD. Separately, parental uncertainty on the number of doses of acetaminophen provided was analyzed. A population attributable fraction (PAF) associated with postnatal acetaminophen exposure before age two for ASD among males was also estimated. Postnatal acetaminophen exposure, measured in doses before age two, was found to be associated with ASD among male children (aOR 1.023, CI 1.005-1.043, $p=0.020^{*}$ ), and parental uncertainty on the number of doses of acetaminophen provided before age two was also found to be associated with ASD. Using this data set, the PAF associated with postnatal acetaminophen was estimated to be about $40 \%$ of the risk of ASD among male children in the US. These results suggest the possibility that postnatal acetaminophen may be a significant contributor to the risk of ASD among males in the US.
\end{abstract}

Keywords: ASD; paracetamol; APAP; ibuprofen; epidemiology; analgesic

\section{Introduction}

An earlier iteration of this paper was presented as a poster session at the International Society for Autism Research Annual Meeting in Montreal, Canada, in May 2019 [1].

Autism spectrum disorder (ASD) is a neurodevelopmental disorder characterized by restricted and repetitive behaviors and deficits in social communication [2]. Two prospective case-control studies have found associations between prenatal maternal acetaminophen exposure and types of ASD [3,4]. Two separate retrospective case-control studies, one of which was conducted by the authors of this article, found that postnatal acetaminophen exposure is associated with increased risk of ASD [5,6].

Additional epidemiological evidence points to a possible role for acetaminophen exposure in the induction of some cases of ASD. For example, Becker and Schultz observed that the highly publicized product tampering cases of cyanide-laced Tylenol brand acetaminophen, which led to significant decreases in acetaminophen sales in 1982 and 1986, coincided with plateaus in the incidence of ASD in California [7]. Separately, a study using Danish medical records found that circumcision in infancy is associated with ASD [8]. The authors of this Danish study hypothesized that this association may be due to the pain of the procedure increasing the risk of ASD [8]. Yet this seems unlikely, as circumcision without analgesia was common throughout history until recent decades [9]. As analgesia for infant circumcision has become more common, acetaminophen has often been used to relieve the pain of the procedure [10]. Thus, an alternative explanation for the association observed between circumcision 
and ASD is that acetaminophen provided coincident or following the procedure may increase the risk of ASD. Others have previously made this same observation [11,12].

Animal studies suggest a connection between postnatal acetaminophen and the development of neurological conditions. In mice, exposure to large doses of acetaminophen early in life has been found to impair behavior and cognitive function in later life $[13,14]$. In rats, exposure to large doses of acetaminophen early in life has been found to degrade neurotransmission, motor function, spatial memory, and social behavior in later life $[15,16]$. In humans, ASD is often associated with poor motor function [17], deficits in spatial working memory [18], and deficits in social behavior [19]. Thus, exposure to large doses of acetaminophen in rodents early in life has lifelong effects that appear to be consistent with some of the characteristics of ASD in humans.

As the authors have observed previously, studies on biochemistry suggest that in general children with ASD metabolize acetaminophen less efficiently than unaffected children [5]. Specifically, in children with ASD, the levels of free sulfate [20,21], reduced glutathione [20-23], cysteine [20-23], and S-adenosyl methionine [20-23] in plasma are significantly lower than in controls. Animal studies have found that decreased availability of each of these same compounds is associated with inefficient metabolism of acetaminophen, and as a result, increased risk of acetaminophen toxicity [24-28]. Indeed, a case-control study of acetaminophen metabolism in children with ASD and unaffected controls found abnormalities in acetaminophen metabolism in those with ASD that suggest those with ASD in aggregate metabolize acetaminophen less efficiently than controls [29].

Some genetic research supports this empirical finding. First, two variants of the SLC13A1 gene, which regulates sulfate transport, are relatively common in ASD [30], and mouse models suggest that these same variants decrease the efficiency of acetaminophen metabolism and increase the propensity for acetaminophen toxicity [31]. Second, genetic variants that decrease the efficiency of the CTH gene increase the risk of ASD [32], and mouse models suggest that such variants increase susceptibility to acetaminophen toxicity [33].

These biochemical and genetic findings suggest that children with ASD in aggregate have greater susceptibility to acetaminophen toxicity than unaffected children. While acetaminophen toxicity is usually viewed as a hepatic issue rather than a neurological one, experiments in rats have found that acetaminophen is toxic to neurons at concentrations below those required to induce acute liver failure [34]. In this light, the above suggests that those with ASD may be at increased risk of neuronal damage from significant acetaminophen exposure. It seems plausible that such neuronal damage may increase the risk of ASD in those who would otherwise be unaffected or exacerbate the pathology of ASD in those who are already affected.

Yet, many practitioners continue to recommend acetaminophen for treating fever in infancy [35], for treating teething pain in infancy [36], and for prophylactic relief of pain during inoculation [37]. Relatedly, acetaminophen is the most widely used over-the-counter medication in infancy and early childhood in the US [38].

It is unclear how the widespread use of acetaminophen in infancy and early childhood is appropriate given the evidence highlighted above. Plausibly, its widespread use may be justified if the association between acetaminophen and ASD that has been observed in human studies is not causative. This possibility seems unlikely to the authors since the studies highlighted above show that acetaminophen has significant negative behavioral and cognitive effects in rodents, that acetaminophen is neurotoxic to rodents, and that the biochemistry and genetics of those with ASD in aggregate suggest that those with ASD may be especially susceptible to the effects of acetaminophen due to inefficient metabolism.

Alternatively, even if postnatal acetaminophen is a causative risk factor for ASD, its continued widespread use in infancy and early childhood could be justified if the contribution to the overall risk of ASD from postnatal acetaminophen is extremely low. Thus, some quantification of the possible risk of ASD in the population in aggregate associated with postnatal acetaminophen exposure has great relevance. This study was initiated to attempt to quantify this potential risk. 
Studies on risk factors for disease often use odds ratios (ORs) as measures of association [39]. However, the magnitude of an OR is a function of the units in which it is measured [40], and an OR does not account for the prevalence of the exposure in the population [41]. Thus, an OR alone will not provide a useful estimate of aggregate risk of a disease due to a particular factor across the population [41]. Population attributable fraction (PAF) is an alternative measure [42]. It represents the proportion of the overall risk of a disease in a population that is associated with a particular factor [42]. Thus, while calculations of ORs are included in this study, an estimate of PAF associated with postnatal acetaminophen is fundamental to it.

\section{Methods}

\subsection{Data Set}

The underlying data for this study was obtained from an Internet-based survey of parents living in the US that was conducted in the Spring of 2017. Survey participants were recruited through Facebook groups, listservs, websites, and the friends of participants. Participants were also recruited with the assistance of the Interactive Autism Network Research Database, a partnership of the Kennedy Krieger Institute and the Simons Foundation.

This same data set was described in a previous article [5]. Parent participants who had a child with ASD were asked about their youngest child with ASD. Parent participants who did not have a child with ASD were asked about their youngest child between ages 3 to 12 . The case set was defined from the former set by further restricting it to consist of only children ages 3 through 12 who had an ASD diagnosis by a professional and who were not known by their parents to have a genetic condition of high penetrance for ASD. The control set was defined from the latter set by further restricting it to consist of children ages 3 through 12 who did not have ASD or a related condition. After exclusions, the sample included 1001 cases and 514 controls.

The survey consisted of between 22 and 25 questions depending upon whether the child in question had ASD. It included one question on the number of doses of acetaminophen consumed by the child before his or her second birthday and another question on the number of doses of ibuprofen consumed by the child before his or her second birthday.

\subsection{Construction of Variables}

A set of dose-dependent categorical variables was constructed to represent the discrete answers to the acetaminophen and ibuprofen questions from the survey. Two separate scaled exposure variables for acetaminophen and ibuprofen were constructed by associating each answer for each range of doses with the lower bound of that range. For example, the answers to the question on the number of doses of acetaminophen provided before age two were: "None", "1-3", "4-15", "16-64", " $64+$ " and "I'm not sure". These answers were associated with numbers: 0, 1, 4, 16, 64, and "not available" (NA).

Demographic variables were also constructed. Some were scaled variables, such as age of the child or education, and others were categorical variables, such as Midwest, which indicated whether the respondent lives in the Midwest. The eight demographic variables considered in this study are: gender, age of the child, ethnicity, Midwest, South, maternal education, age of mother at birth of child, and relationship to the child.

\subsection{Statistical Analysis}

Analyses were run using the $\mathrm{R}$ statistical package. The threshold for statistical significance on $p$-values in this study was set to be 0.05 . Crude dose-dependent Wald ORs and 95\% confidence intervals (CIs) were computed for the acetaminophen and ibuprofen categorical variables against the outcome of ASD. 
Logistic regressions were run to compute ORs and adjusted odds ratios (aORs) for scaled variables acetaminophen, ibuprofen, and the two jointly. Analogous calculations were run for males-only and females-only subsets. Categorical aORs were also computed for each acetaminophen dose stratum.

A consistent set of demographic covariates was used for all logistic regressions with covariates against the outcome of ASD using the following procedure. For each of the two scaled analgesic variables in the full data set, a preliminary logistic regression was run where the candidate set of covariates consisted of the eight demographic variables against the outcome of ASD. Variable selection in these preliminary logistic regressions was made using the Akaike information criterion (AIC). AIC is a measure of relative model quality [43]. The union of all covariates included in each of these two logistic regressions was used as the set of demographic covariates to be included in all logistic regressions with covariates against the outcome of ASD.

Tests for interaction between each of the scaled analgesic variables and gender against the outcome of ASD were also conducted using logistic regressions with interaction terms.

To determine if any variables are associated with the parent not knowing how many doses of acetaminophen the child consumed, logistic regressions were run to compute aORs for the outcome of "NA for acetaminophen". Potential covariates were the eight demographic variables and ASD status. Variable selection was determined objectively using AIC. The same procedure was followed to obtain aORs for the outcome of "NA for ibuprofen".

Percentages of male cases exposed to each discrete dose stratum of postnatal acetaminophen were obtained directly from the data set. The PAF among males was calculated for each acetaminophen dose stratum using a standard formula for PAF for variables with exposure levels as provided by Rockhill and derived by Walter and Kleinbaum [42,44,45]:

$$
\frac{p_{i}\left(R R_{i}-1\right)}{1+\sum_{j=0}^{k} p_{j}\left(R R_{j}-1\right)}
$$

This formula provides the PAF for stratum $i$ where there are $\mathrm{k}$ strata in total, $p_{j}$ is the proportion of the case population exposed to stratum $j$, and $R R_{j}$ is the risk ratio between cases and controls for stratum $j$.

Using the rare disease assumption as defined by Greenland and Thomas [46], the risk ratio for each dose stratum was approximated by the categorical aOR for that dose stratum. The aggregate PAF associated with postnatal acetaminophen was then obtained by summing the per stratum PAF across the acetaminophen strata.

\section{Results}

\subsection{Demographics}

Table 1 provides the demographic characteristics of the participants. It is an abridged and edited version of an analogous table from the authors' previous article that relied on this data set [5]. To summarize, case children were 1.8 years older than controls and were somewhat more ethnically diverse than controls. Relatively more case children lived in the South and relatively less were from the Midwest than controls. Case mothers were 1.2 years younger than control mothers and somewhat less well-educated in aggregate than control mothers.

Table 1. Demographics.

\begin{tabular}{lcc}
\hline Variable & Cases & Controls \\
\hline$n$ & 1001 & 514 \\
Gender of child-male $(n, \%)$ & $801(80.0)$ & $268(52.1)$ \\
Age of child (mean, SD) & $7.3(2.9)$ & $5.5(2.6)$ \\
Maternal age at birth of child (mean, SD) & $30.0(5.6)$ & $31.2(4.6)$ \\
\hline
\end{tabular}


Table 1. Cont.

\begin{tabular}{lcc}
\hline Variable & Cases & Controls \\
\hline Ethnicity of child $(n, \%)$ & & \\
White (non-Hispanic) & $773(77.2)$ & $438(85.2)$ \\
Hispanic/Latino & $104(10.4)$ & $30(5.8)$ \\
African American/Black & $39(3.9)$ & $5(1.0)$ \\
Asian & $19(1.9)$ & $11(2.1)$ \\
Other & $66(6.6)$ & $30(5.8)$ \\
\hline Regions of residence in US $(n, \%)$ & & \\
Northeast & $180(18.0)$ & $103(20.0)$ \\
Midwest & $240(24.0)$ & $176(34.2)$ \\
South & $362(36.2)$ & $108(21.0)$ \\
West & $219(21.9)$ & $127(24.7)$ \\
\hline Maternal education $(n, \%)$ & & \\
Grade school or some high school & $10(1.0)$ & $6(1.2)$ \\
High school & $80(8.0)$ & $22(4.3)$ \\
Some college & $272(27.2)$ & $72(14.0)$ \\
Bachelor's or Associate's degree & $394(39.4)$ & $208(40.5)$ \\
Graduate or professional degree & $244(24.4)$ & $206(40.1)$ \\
I'm not sure & $1(0.1)$ & - \\
\hline Relationship to child $(n, \%)$ & \multicolumn{2}{l}{} \\
Biological mother & $978(97.7)$ & $497(96.7)$ \\
Biological father & $21(2.1)$ & $15(2.9)$ \\
NA & $2(0.2)$ & $2(0.4)$ \\
\hline A & &
\end{tabular}

Abbreviations: SD, standard deviation; \%, percentage of cases or controls.

\subsection{Crude Dose-Dependent Wald ORs}

Table 2 provides aggregate, males-only, and females-only crude dose-dependent Wald ORs for acetaminophen and ibuprofen against the outcome of ASD. Two of these dose-dependent variables have statistically significant associations: $64+$ doses of acetaminophen and 64+ doses of acetaminophen in males.

Table 2. Dose dependent Wald ORs relative to no exposure.

\begin{tabular}{|c|c|c|c|c|c|c|}
\hline & & Cases & Controls & & & \\
\hline Exposure & Dose & $n(\%)$ & $n(\%)$ & OR & $95 \% \mathrm{CI}$ & $p$-Value \\
\hline \multirow{6}{*}{ Acetaminophen } & None & $54(5.4)$ & $45(8.8)$ & & Reference & \\
\hline & $1-3$ & $174(17.4)$ & 91 (17.7) & 1.593 & $0.996-2.549$ & 0.0511 \\
\hline & $4-15$ & $378(37.8)$ & $216(42.0)$ & 1.458 & $0.949-2.241$ & 0.0839 \\
\hline & $16-63$ & $191(19.1)$ & $107(20.8)$ & 1.488 & $0.938-2.359$ & 0.0904 \\
\hline & $64+$ & $26(2.6)$ & $4(0.8)$ & 5.417 & $1.759-16.68$ & 0.0015 * \\
\hline & Not sure & $178(17.8)$ & $51(9.9)$ & - & - & - \\
\hline \multirow{6}{*}{ Ibuprofen } & None & $185(18.5)$ & $115(22.4)$ & & Reference & \\
\hline & $1-3$ & $167(16.7)$ & $91(17.7)$ & 1.141 & $0.808-1.612$ & 0.4549 \\
\hline & $4-15$ & $304(30.4)$ & $180(35.0)$ & 1.050 & $0.780-1.413$ & 0.7481 \\
\hline & $16-63$ & $141(14.1)$ & $74(14.4)$ & 1.184 & $0.822-1.706$ & 0.3634 \\
\hline & $64+$ & 17 (1.7) & $6(1.2)$ & 1.761 & $0.675-4.597$ & 0.2422 \\
\hline & Not sure & 187 (18.7) & $48(9.3)$ & - & - & - \\
\hline \multirow{6}{*}{$\begin{array}{l}\text { Acetaminophen } \\
\text { in males }\end{array}$} & None & $37(4.6)$ & $20(7.5)$ & & Reference & \\
\hline & $1-3$ & $134(16.7)$ & $52(19.4)$ & 1.393 & $0.741-2.619$ & 0.3023 \\
\hline & $4-15$ & $308(38.5)$ & $110(41)$ & 1.514 & $0.842-2.719$ & 0.1634 \\
\hline & $16-63$ & $156(19.5)$ & $55(20.5)$ & 1.533 & $0.821-2.864$ & 0.1782 \\
\hline & $64+$ & $21(2.6)$ & $2(0.7)$ & 5.676 & $1.206-26.72$ & 0.0167 * \\
\hline & Not sure & 145 (18.1) & $29(10.8)$ & - & - & - \\
\hline
\end{tabular}


Table 2. Cont.

\begin{tabular}{|c|c|c|c|c|c|c|}
\hline & & Cases & Controls & & & \\
\hline Exposure & Dose & $n(\%)$ & $n(\%)$ & OR & $95 \%$ CI & $p$-Value \\
\hline \multirow{6}{*}{$\begin{array}{l}\text { Ibuprofen in } \\
\text { males }\end{array}$} & None & 147 (18.4) & $61(22.8)$ & & Reference & \\
\hline & $1-3$ & $126(15.7)$ & 47 (17.5) & 1.112 & $0.740-1.742$ & 0.6415 \\
\hline & $4-15$ & 245 (30.6) & $83(31)$ & 1.225 & $0.830-1.807$ & 0.3060 \\
\hline & $16-63$ & 118 (14.7) & 44 (16.4) & 1.113 & $0.705-1.758$ & 0.6465 \\
\hline & $64+$ & 13 (1.6) & $3(1.1)$ & 1.798 & $0.495-6.535$ & 0.3668 \\
\hline & Not sure & $152(19)$ & 30 (11.2) & - & - & - \\
\hline \multirow{6}{*}{$\begin{array}{l}\text { Acetaminophen } \\
\text { in females }\end{array}$} & None & $17(8.5)$ & $25(10.2)$ & & Reference & \\
\hline & $1-3$ & $40(20)$ & 39 (15.9) & 1.508 & $0.707-3.218$ & 0.2866 \\
\hline & $4-15$ & $70(35)$ & $106(43.1)$ & 0.971 & $0.489-1.929$ & 0.9333 \\
\hline & $16-63$ & 35 (17.5) & $52(21.1)$ & 0.990 & $0.467-2.097$ & 0.9787 \\
\hline & $64+$ & $5(2.5)$ & $2(0.8)$ & 3.677 & $0.638-21.19$ & 0.1274 \\
\hline & Not sure & 33 (16.5) & $22(8.9)$ & - & - & - \\
\hline \multirow{6}{*}{$\begin{array}{l}\text { Ibuprofen in } \\
\text { females }\end{array}$} & None & $38(19)$ & $54(22)$ & & Reference & \\
\hline & $1-3$ & $41(20.5)$ & 44 (17.9) & 1.324 & $0.731-2.399$ & 0.3541 \\
\hline & $4-15$ & 59 (29.5) & $97(39.4)$ & 0.864 & $0.511-1.463$ & 0.5871 \\
\hline & $16-63$ & $23(11.5)$ & $30(12.2)$ & 1.089 & $0.550-2.158$ & 0.8059 \\
\hline & $64+$ & $4(2)$ & $3(1.2)$ & 1.895 & $0.401-8.957$ & 0.4137 \\
\hline & Not sure & $35(17.5)$ & $18(7.3)$ & - & - & - \\
\hline
\end{tabular}

Notes: ${ }^{*}$ for $p$ values $<0.05$. Abbreviations: OR, Wald odds ratio; $95 \%$ CI, 95\% Wald confidence interval.

\subsection{Gender-Specific ORs and aORs}

Table 3 provides aggregate, males-only, and females-only ORs and aORs for the scaled variables acetaminophen and ibuprofen against the outcome of ASD. Based on the procedure highlighted in the methods section, using AIC, all eight demographic variables were included as covariates in the aORs in the full data set- - they are: gender, age of the child, ethnicity, Midwest, South, maternal education, age of mother at birth of child, and relationship. These same variables with the exception of gender were used as covariates in the gender-specific models.

Table 3. Gender-specific ORs and aORs for scaled variables.

\begin{tabular}{cccccccc}
\hline & & & Unadjusted & \multicolumn{3}{c}{ Adjusted for Demographics } \\
\hline \multirow{2}{*}{ Set } & Variable & OR & $\mathbf{9 5 \% ~ C I ~}$ & $p$-Value & aOR a & 95\% CI & $p$-Value \\
\hline \multirow{2}{*}{ Full set } & Acetaminophen (doses) & 1.015 & $1.003-1.028$ & $0.018^{*}$ & 1.016 & $1.003-1.032$ & $0.0259^{*}$ \\
& Ibuprofen (doses) & 1.008 & $0.996-1.021$ & 0.210 & 1.012 & $0.997-1.027$ & 0.1106 \\
\hline \multirow{2}{*}{ Males-only } & Acetaminophen (doses) & 1.017 & $1.001-1.036$ & $0.046^{*}$ & 1.023 & $1.005-1.043$ & $0.0200^{*}$ \\
& Ibuprofen (doses) & 1.006 & $0.991-1.024$ & 0.464 & 1.014 & $0.997-1.034$ & 0.1356 \\
\hline \multirow{2}{*}{ Females-only } & Acetaminophen (doses) & 1.009 & $0.988-1.031$ & 0.401 & 1.005 & $0.981-1.030$ & 0.7196 \\
& Ibuprofen (doses) & 1.007 & $0.986-1.029$ & 0.521 & 1.007 & $0.982-1.033$ & 0.5737 \\
\hline
\end{tabular}

Notes: ${ }^{a}$ Covariates for the aORs are: gender, age of the child, ethnicity, Midwest, South, maternal education, age of mother at birth of child, and relationship. ${ }^{*}$ for $p$-values $<0.05$. Abbreviations: OR, odds ratio; aOR, adjusted odds ratio; $95 \% \mathrm{CI}, 95 \%$ confidence interval.

With respect to gender-specific interaction effects, the $p$-value of an acetaminophen $\mathrm{X}$ gender variable in a regression with acetaminophen, gender and covariates is 0.253 , and the $p$-value of an ibuprofen $X$ gender variable in an analogous regression with ibuprofen, gender, and covariates is 0.723 .

Table 4 provides statistics on a joint model including both acetaminophen and ibuprofen and males-only and females-only versions of this same model. 
Table 4. Joint models for scaled variables.

\begin{tabular}{cccccc}
\hline Set & $\boldsymbol{n}$ & Variable & aOR $^{\mathbf{a}}$ & $\mathbf{9 5 \%} \mathbf{C I}$ & $\boldsymbol{p}$-Value \\
\hline \multirow{2}{*}{ Full set } & \multirow{2}{*}{1257} & Acetaminophen (doses) & 1.018 & $0.998-1.039$ & 0.0892 \\
& & Ibuprofen (doses) & 1.000 & $0.979-1.020$ & 0.9701 \\
\hline \multirow{2}{*}{ Males-only } & \multirow{2}{*}{871} & Acetaminophen (doses) & 1.025 & $1.001-1.053$ & 0.0577 \\
& & Ibuprofen (doses) & 0.998 & $0.973-1.024$ & 0.8713 \\
\hline \multirow{2}{*}{ Females-only } & \multirow{2}{*}{386} & Acetaminophen (doses) & 1.002 & $0.968-1.041$ & 0.8960 \\
& & Ibuprofen (doses) & 1.004 & $0.965-1.040$ & 0.8295 \\
\hline
\end{tabular}

Notes: a Covariates for the aORs are: gender, age of the child, ethnicity, Midwest, South, maternal education, age of mother at birth of child, and relationship. Abbreviations: aOR, adjusted odds ratio; $95 \% \mathrm{CI}, 95 \%$ confidence interval.

\section{4. aORs for NA for Acetaminophen and NA for Ibuprofen}

Table 5 provides aORs for the demographic variables and ASD regressed against the outcomes of "NA for acetaminophen" and "NA for ibuprofen" using AIC as the criteria for variable inclusion.

Table 5. aORs for not available (NA) for acetaminophen and NA for ibuprofen.

\begin{tabular}{cccccc}
\hline Model & $n$ & Variable & aOR $^{\text {a }}$ & 95\% CI & $p$-Value \\
\hline \multirow{2}{*}{ NA for } & \multirow{2}{*}{1514} & Age of Child & 1.141 & $1.085-1.201$ & $<0.0001^{*}$ \\
Acetaminophen & ASD & 1.466 & $1.040-2.095$ & $0.0318^{*}$ \\
& & Education & 0.846 & $0.724-0.991$ & $0.0372^{*}$ \\
\hline \multirow{2}{*}{ NA for } & \multirow{2}{*}{1514} & Age of Child & 1.144 & $1.088-1.203$ & $<0.0001^{*}$ \\
Ibuprofen & & Education & 0.827 & $0.708-0.967$ & $0.0171^{*}$ \\
& & ASD & 1.539 & $1.074-2.237$ & $0.0210^{*}$ \\
& & Gender (male) & 1.307 & $0.931-1.860$ & 0.1289 \\
\hline
\end{tabular}

Notes: a Covariates for the aORs are: gender, age of the child, ethnicity, Midwest, South, maternal education, age of mother at birth of child, and relationship. ${ }^{*}$ for $p$-values $<0.05$. Abbreviations: aOR, adjusted Odds Ratio; $95 \% \mathrm{CI}$, $95 \%$ confidence interval.

\subsection{PAF for ASD Associated with Acetaminophen among Males}

Table 6 provides statistics on each acetaminophen dose stratum, aORs for acetaminophen for each stratum, and the calculated PAF per stratum. Summing the PAFs across strata, the PAF for ASD associated with postnatal acetaminophen among males is estimated to be $43.7 \%$.

Table 6. PAF associated with postnatal acetaminophen among males by strata.

\begin{tabular}{ccccc}
\hline Acetaminophen Doses & Cases $\boldsymbol{n} \mathbf{( \% )}$ & aOR $^{\mathbf{a}}$ & $\mathbf{9 5} \% \mathbf{C I}$ & PAF (\%) \\
\hline None & $37(5.6)$ & Reference & & \\
$1-3$ & $134(20.4)$ & 1.360 & $0.683-2.680$ & 4.13 \\
$4-15$ & $308(47)$ & 1.685 & $0.881-3.165$ & 18.11 \\
$16-63$ & $156(23.8)$ & 1.824 & $0.909-3.616$ & 11.03 \\
$64+$ & $21(3.2)$ & 6.805 & $1.595-47.633$ & 10.45 \\
\hline
\end{tabular}

Notes: a Covariates for the aORs are: age of the child, ethnicity, Midwest, South, maternal education, age of mother at birth of child, and relationship. Abbreviations: aOR, adjusted odds ratio; $95 \%$ CI, 95\% confidence interval; PAF, population attributable fraction.

\section{Discussion}

\subsection{Demographics}

The demographic differences between the case and control sets are generally explainable based on the construction of the survey and ASD epidemiology. For example, control parents were asked about their youngest child between 3 and 12 years old, while case parents were asked about their youngest child with ASD. It seems certain that many of the case parents, who answered as instructed regarding 
their youngest child with ASD, actually had a younger unaffected child between 3 and 12 years old. Thus, by construction, one would expect the average age of case children to be older than the average age of control children. In addition, ASD is often diagnosed late [47]. This would also suggest an older age for case children in this study, since some of the younger control children might later be diagnosed with ASD. Thus, it is not surprising that cases were on average 1.8 years older than controls.

\subsection{Units}

While most of the aORs in this study for the scaled variables may seem small in magnitude, the magnitude of ORs and aORs are dependent on the units of the underlying variables [40]. In this study, the scaled acetaminophen and ibuprofen variables are measured in units of doses provided before age two. If instead these variables were expressed as dichotomous variables relative to a threshold number of doses, the magnitude of the aORs would be much larger.

\subsection{Possible Recall Bias}

In some retrospective studies on severe disease, case respondents may overestimate the subject's exposure to variables that they believe could be factors in inducing the disease [48]. While such recall bias does not always occur, in cases where it does occur, it can tilt results toward an association between the exposure in question and the disease [48-50].

An important question is whether recall bias played a significant role in the results of this study. It is notable that among the two analgesic scaled exposure variables in this study, the associations with acetaminophen are much stronger than with ibuprofen. Thus, if recall bias did significantly affect the results for the analgesic variables, its role seems to have been significantly greater for the acetaminophen variable than for the ibuprofen variable. Also, recall bias did not appear to affect results on a vitamin $\mathrm{D}$ drop variable and a prenatal folate variable that were collected simultaneously [5]. Specifically, as the authors noted in their previous study with this data set, the survey responses suggested that oral vitamin D drop exposure is weakly associated with ASD after adjusting for covariates, and prenatal folate has no association with ASD but the aOR is in the direction of increasing risk [5]. If recall bias was fundamental to these results, the expected directions of association with vitamin D drops and folate would be in the opposite direction of what was observed.

Also, in the present study, a statistically significant association was found between the "I'm not sure" response on the acetaminophen question and ASD. It seems unlikely that such a disproportionate "I'm not sure" response among cases would be a result of recall bias, as the usual pattern when recall bias does occur is that case participants recall exposures that did not occur or over-estimate exposures that did occur [48].

\subsection{Gender-Specific ORs and aORs}

Table 2 highlights that $64+$ doses of acetaminophen before age two has a statistically significant association with ASD. The OR is greater in magnitude for the analogous variable in the males-only set. While the results in this table also suggest the possibility of associations with acetaminophen at more modest doses and potential associations with ibuprofen, none of the other results from this table are statistically significant.

The $p$-values from Table 3 show that the association of the males-only acetaminophen scaled variable with ASD is statistically significant, while the females-only acetaminophen scaled variable is far from statistically significant. Similarly, the aOR for the males-only acetaminophen variable is much greater in magnitude than the analogous females-only variable. As there are more males than females in this data set, one might be tempted to attribute the much weaker association among females to the greater number of males in the sample.

However, the $p$-values and aORs for acetaminophen in the males-only set and the full data set suggest the possibility that the association between acetaminophen and ASD is somewhat stronger in the males-only set than in the full set, despite the fact that the males-only set is significantly 
smaller. In addition, the acetaminophen results contrast with the ibuprofen results, where in general, the associations are much weaker and are not characterized by a stronger association among males than in the full set.

While the $p$-value for the interaction term with acetaminophen is much lower than with ibuprofen, neither one is statistically significant. One possibility is that there is no interaction effect with gender for either of these variables. Another possibility is that there is an interaction effect, but the sample was insufficiently sized to show it based on a $p$-value threshold of 0.05 . This seems plausible for acetaminophen, as sample sizes required to accurately measure interaction effects are much larger than sample sizes needed for measuring primary effects [51].

While Table 3 hints at a possible weak association between ibuprofen and ASD, the much larger $p$-values for ibuprofen in the joint models from Table 4 indicate that any association between ibuprofen and ASD could conceivably be a result of ibuprofen use being correlated with acetaminophen use.

\subsection{Potential Confounders}

A natural question is whether other variables that were not examined in this study could explain the relatively strong association observed between postnatal acetaminophen and ASD among males. One possibility is that cases may have greater indications of use for acetaminophen than controls. For example, it is plausible that cases, who are those who later receive an ASD diagnosis, could have greater susceptibility to fevers and hence be more likely to receive acetaminophen than controls.

If this scenario is driving the association between acetaminophen and ASD observed in this study, then one would expect a similarly strong association between ibuprofen and ASD, as both are used as antipyretics. Yet, the associations between ibuprofen and ASD observed in this study are much weaker than those between acetaminophen and ASD, and this is especially true among males.

Another potential cofounder is prenatal maternal acetaminophen exposure. As highlighted in the Introduction, prenatal maternal acetaminophen exposure has been found to be associated with ASD [3,4]. There is also evidence that maternal use of acetaminophen tends to be correlated with use in school children [52]. Thus, it seems plausible that prenatal acetaminophen exposure is a correlated variable that could be causative and confounding.

However, other factors in addition to maternal use may be involved in parental proclivity to provide over-the-counter medications to their children [53,54]. In addition, the associations between prenatal acetaminophen and ASD from the literature seem to be relatively weak, despite being obtained from large data sets [3,4]. Thus, it seems unlikely that a correlation with prenatal acetaminophen, a variable with relatively weak association with ASD, would fully explain the strong association observed between postnatal acetaminophen among males and ASD observed in the present study with a smaller data set.

\subsection{NA for Acetaminophen and NA for Ibuprofen}

Table 5 shows that demographic factors alone do not account for the pattern of NA responses on the acetaminophen and ibuprofen questions observed in this study. Specifically, AIC results in the inclusion of ASD status as a statistically significant variable in regression models for the outcome of NA responses. This suggests that the pattern of NA responses for these variables can be seen as additional confirmation of an association between analgesic use and ASD status.

Recall that NA responses came from respondents who selected "I'm not sure". For example, on the acetaminophen question, the parent respondents who selected this answer would have been those who were uncertain about how many doses of acetaminophen were consumed by their child. It seems probable to the authors that a parent would have remembered if acetaminophen was never provided to her child or if it was only provided rarely. Thus, the NA responses on the acetaminophen question may be indicative of higher than average levels of acetaminophen exposure. As ASD is statistically significantly associated with NA responses on the acetaminophen question from Table 5, calculations 
which exclude NA responses like those in Table 3 may underestimate the strength of the association between acetaminophen and ASD. The same is true of the association between ibuprofen and ASD.

\subsection{PAF for ASD Associated with Acetaminophen among Males}

There is considerable imprecision around the estimate of PAF for ASD associated with postnatal acetaminophen exposure among males. As noted above, the risk ratios were approximated by the aORs for the dose strata in the PAF calculations. Greenland and Thomas found that this approximation is only likely to induce significant bias in cases where the prevalence of the disease in the population in question is greater than $10 \%$ [46]. As ASD prevalence among eight-year-old males is about $2.7 \%$ per Baio et al. [55], this approximation is unlikely to induce significant bias in the PAF calculation.

While this approximation is unlikely to introduce significant bias, the aORs on the acetaminophen per dose strata are imprecise, especially for the lower dose strata where the CIs are wide. As these aORs are fundamental to the PAF calculation, this imprecision introduces imprecision into the PAF estimate.

In addition, while the aORs for the dose strata were adjusted for seven covariates, it seems likely that there may be other variables, which are correlated with postnatal acetaminophen exposure and are not included in this analysis, that may contribute to ASD risk. For example, these might include indications of use and prenatal acetaminophen. As previously explored, it seems unlikely that either of these variables would fully account for the association between postnatal acetaminophen and ASD observed in this study, but either of these variables could account for a portion of this association. In a scenario where such correlated variables contribute to risk, the PAF could be overestimated [56].

Conversely, it is possible that the aOR for acetaminophen among males is underestimated due to the disproportionate "I'm not sure" responses among case participants. As explored above, these responses may have resulted in relative underestimation of higher dose exposure among case children. This scenario would tend to lead to underestimation of the PAF.

Thus, while the data presented here suggests that there is a non-trivial PAF associated with postnatal acetaminophen among males, there is significant imprecision around this estimate.

The reader may wonder why the authors have not calculated the PAF for postnatal acetaminophen among females. Given that any association between acetaminophen exposure and ASD among females is not statistically significant in this data set, as Table 3 indicates, and relatedly the CIs are as a result very wide, the authors do not believe a meaningful estimate of the PAF for ASD among females can be obtained using this data set.

\subsection{Strengths and Limitations}

Some limitations of this study arose from its reliance on a data set that was based on an Internet survey. For example, parents' answers to survey questions were not independently verified. In addition, information on the size of the doses provided was not obtained. It also would have been desirable if there were greater demographic similarity between the case and control sets. In addition, the significant number of NA responses on the acetaminophen question increases the uncertainty around the results obtained, even if this uncertainty likely points in the direction of increased risk.

A strength of this study is that it rigorously shows that uncertainty on the number of doses of acetaminophen provided before age two is associated with ASD. Separately, expressing the main result from this study as a PAF offers additional transparency and clarity on its potential relevance.

\section{Conclusions}

This study finds that postnatal acetaminophen measured in doses consumed before age two is associated with ASD risk in male children (aOR 1.023, CI 1.005-1.043, $p=0.020 *$ ). If this data set is representative, then the PAF for postnatal acetaminophen is approximately $40 \%$ of the risk of ASD among males in the US. This may be an overestimate, as other correlated variables that were not included in this analysis may also contribute to risk of ASD. While it is possible that the association between postnatal acetaminophen and ASD in males is not causative, this study shows that if the 
association is causative, the contribution to risk in aggregate from this variable may be a substantial portion of the risk of ASD. Prospective studies on this variable are needed.

Author Contributions: Conceptualization, S.S.B., K.R.B.; Data curation, S.S.B.; Formal analysis, S.S.B., K.R.B.; Investigation, S.S.B., K.R.B.; Methodology, S.S.B., K.R.B.; Project administration, S.S.B.; Resources, S.S.B.; Software, S.S.B.; Validation, S.S.B., K.R.B.; Visualization, S.S.B., K.R.B.; Writing-original draft, S.S.B., K.R.B.; Writing-review \& editing, S.S.B., K.R.B. Both authors have read and agreed to the published version of the manuscript. All authors have read and agreed to the published version of the manuscript.

Funding: This research received no external funding.

Acknowledgments: To obtain the data set used in this study, the authors benefited from the facilities, resources, administrative, institutional and research support provided by Columbia University's Interdisciplinary Center for Innovative Theory and Empirics (INCITE). In addition, the authors are grateful to the Interactive Autism Network Research Database (IAN) for its generous assistance with subject recruitment. We are also very grateful to the parents who took the time to participate in the survey as well as the administrators, executive directors, and presidents of various groups who graciously permitted the survey to be highlighted through their media. We especially wish to express our gratitude to Peter Bearman and Michael Falco of INCITE.

Conflicts of Interest: The authors declare no conflict of interest.

\section{Abbreviations}

$\begin{array}{ll}\text { aOR } & \text { Adjusted odds ratio } \\ \text { ASD } & \text { Autism spectrum disorder } \\ \text { CI } & 95 \% \text { confidence interval } \\ \text { OR } & \text { Odds ratio } \\ \text { NA } & \text { Not available } \\ \text { PAF } & \text { Population attributable fraction } \\ \text { US } & \text { United States }\end{array}$

\section{References}

1. Bittker, S.S.; Bell, K.R. Postnatal Acetaminophen: Contribution to Risk of Autism Spectrum Disorder among Males. In Proceedings of the International Society for Autism Research Annual Meeting, Montreal, QC, Canada, 4 May 2019. Available online: https://insar.confex.com/insar/2019/webprogram/Paper29891.html (accessed on 30 December 2019).

2. American Psychiatric Association. Diagnostic and Statistical Manual of Mental Disorders, 5th ed.; American Psychiatric Publishing: Arlington, VA, USA, 2013.

3. Liew, Z.; Ritz, B.; Virk, J.; Olsen, J. Maternal use of acetaminophen during pregnancy and risk of autism spectrum disorders in childhood: A Danish national birth cohort study. Autism Res. 2016, 9, 951-958. [CrossRef] [PubMed]

4. Avella-Garcia, C.B.; Julvez, J.; Fortuny, J.; Rebordosa, C.; García-Esteban, R.; Galan, I.R.; Tardon, A.; Rodríguez-Bernal, C.L.; Iñiguez, C.; Andiarena, A.; et al. Acetaminophen use in pregnancy and neurodevelopment: Attention function and autism spectrum symptoms. Int. J. Epidemiol. 2016, 45, 1987-1996. [CrossRef] [PubMed]

5. Bittker, S.S.; Bell, K.R. Acetaminophen, antibiotics, ear infection, breastfeeding, vitamin D drops, and autism: An epidemiological study. Neuropsychiatr. Dis. Treat. 2018, 14, 1399-1414. [CrossRef] [PubMed]

6. Schultz, S.T.; Klonoff-Cohen, H.S.; Wingard, D.L.; Akshoomoff, N.A.; Macera, C.A.; Ji, M. Acetaminophen (paracetamol) use, measles-mumps-rubella vaccination, and autistic disorder: The results of a parent survey. Autism 2008, 12, 293-307. [CrossRef] [PubMed]

7. Becker, K.G.; Schultz, S.T. Similarities in features of autism and asthma and a possible link to acetaminophen use. Med. Hypotheses 2010, 74, 7-11. [CrossRef] [PubMed]

8. Frisch, M.; Simonsen, J. Ritual circumcision and risk of autism spectrum disorder in 0- to 9-year-old boys: National cohort study in Denmark. J. R. Soc. Med. 2015, 108, 266-279. [CrossRef]

9. Poma, P.A. Painless neonatal circumcision. Int. J. Gynaecol. Obstet. 1980, 18, 308-309. [CrossRef]

10. Bellieni, C.V.; Alagna, M.G.; Buonocore, G. Analgesia for infants' circumcision. Ital. J. Pediatr. 2013, $39,38$. [CrossRef] 
11. Morris, B.J.; Wiswell, T.E. 'Circumcision pain' unlikely to cause autism. J. R. Soc. Med. 2015, $108,297$. [CrossRef]

12. Parker, W.; Hornik, C.D.; Bilbo, S.; Holzknecht, Z.E.; Gentry, L.; Rao, R.; Lin, S.S.; Herbert, M.R.; Nevison, C.D. The role of oxidative stress, inflammation and acetaminophen exposure from birth to early childhood in the induction of autism. J. Int. Med. Res. 2017, 45, 407-438. [CrossRef]

13. Philippot, G.; Gordh, T.; Fredriksson, A.; Viberg, H. Adult neurobehavioral alterations in male and female mice following developmental exposure to paracetamol (acetaminophen): Characterization of a critical period. J. Appl. Toxicol. 2017, 37, 1174-1181. [CrossRef] [PubMed]

14. Viberg, H.; Eriksson, P.; Gordh, T.; Fredriksson, A. Paracetamol (acetaminophen) administration during neonatal brain development affects cognitive function and alters its analgesic and anxiolytic response in adult male mice. Toxicol. Sci. 2014, 138, 139-147. [CrossRef] [PubMed]

15. Blecharz-Klin, K.; Piechal, A.; Jawna-Zboińska, K.; Pyrzanowska, J.; Wawer, A.; Joniec-Maciejak, I.; Widy-Tyszkiewicz, E. Paracetamol-Effect of early exposure on neurotransmission, spatial memory and motor performance in rats. Behav. Brain Res. 2017, 323, 162-171. [CrossRef] [PubMed]

16. Blecharz-Klin, K.; Wawer, A.; Jawna-Zboińska, K.; Pyrzanowska, J.; Piechal, A.; Mirowska-Guzel, D.; Widy-Tyszkiewicz, E. Early paracetamol exposure decreases brain-derived neurotrophic factor (BDNF) in striatum and affects social behaviour and exploration in rats. Pharmacol. Biochem. Behav. 2018, 168, 25-32. [CrossRef] [PubMed]

17. Lloyd, M.; MacDonald, M.; Lord, C. Motor skills of toddlers with autism spectrum disorders. Autism 2013, 17, 133-146. [CrossRef] [PubMed]

18. Steele, S.D.; Minshew, N.J.; Luna, B.; Sweeney, J.A. Spatial working memory deficits in autism. J. Autism Dev. Disord. 2007, 37, 605-612. [CrossRef] [PubMed]

19. Gizzonio, V.; Avanzini, P.; Campi, C.; Orivoli, S.; Piccolo, B.; Cantalupo, G.; AlbertoTassinari, C.; Rizzolatti, G.; Fabbri-Destr, M. Failure in pantomime action execution correlates with the severity of social behavior deficits in children with autism: A praxis study. J. Autism Dev. Disord. 2015, 45, 3085-3097. [CrossRef]

20. Adams, J.B.; Audhya, T.; McDonough-Means, S.; Rubin, R.A.; Quig, D.; Geis, E.; Gehn, E.; Loresto, M.; Mitchell, J.; Atwood, S.; et al. Nutritional and metabolic status of children with autism vs. neurotypical children, and the association with autism severity. Nutr. Metab. 2011, 8, 34. [CrossRef]

21. Geier, D.A.; Kern, J.K.; Garver, C.R.; Adams, J.B.; Audhya, T. A prospective study of transsulfuration biomarkers in autistic disorders. Neurochemical. Res. 2008, 34, 386-393. [CrossRef]

22. James, S.J.; Cutler, P.; Melnyk, S.; Jernigan, S.; Janak, L.; Gaylor, D.W.; Neubrander, J.A. Metabolic biomarkers of increased oxidative stress and impaired methylation capacity in children with autism. Am. J. Clin. Nutr. 2004, 80, 1611-1617. [CrossRef]

23. Melnyk, S.; Fuchs, G.J.; Schulz, E.; Lopez, M.; Kahler, S.G.; Fussell, J.J.; Bellando, J.; Pavliv, O.; Rose, S.; Seidel, L.; et al. Metabolic imbalance associated with methylation dysregulation and oxidative damage in children with autism. J. Autism Dev. Disord. 2012, 42, 367-377. [CrossRef] [PubMed]

24. Zhao, P.; Kalhorn, T.F.; Slattery, J.T. Selective mitochondrial glutathione depletion by ethanol enhances acetaminophen toxicity in rat liver. Hepatology 2002, 36, 326-335. [CrossRef] [PubMed]

25. Gregus, Z.; Kim, H.J.; Madhu, C.; Liu, Y.; Rozman, P.; Klaassen, C.D. Sulfation of acetaminophen and acetaminophen-induced alterations in sulfate and 3'-phosphoadenosine 5'-phosphosulfate homeostasis in rats with deficient dietary intake of sulfur. Drug Metab. Dispos. 1994, 22, 725-730. [PubMed]

26. Price, V.F.; Jollow, D.J. Effects of sulfur-amino acid-deficient diets on acetaminophen metabolism and hepatotoxicity in rats. Toxicol. Appl. Pharmacol. 1989, 101, 356-369. [CrossRef]

27. Lauterburg, B.H.; Corcoran, G.B.; Mitchell, J.R. Mechanism of action of N-acetylcysteine in the protection against the hepatotoxicity of acetaminophen in rats in vivo. J. Clin. Investig. 1983, 71, 980-991. [CrossRef]

28. Terneus, M.V.; Kiningham, K.K.; Carpenter, A.B.; Sullivan, S.B.; Valentovic, M.A. Comparison of S-Adenosyl-L-methionine and $\mathrm{N}$-acetylcysteine protective effects on acetaminophen hepatic toxicity. J. Pharmacol. Exp. Ther. 2007, 320, 99-107. [CrossRef]

29. Alberti, A.; Pirrone, P.; Elia, M.; Waring, R.H.; Romano, C. Sulphation deficit in "low-functioning" autistic children: A pilot study. Biol. Psychiatry 1999, 46, 420-424. [CrossRef]

30. Bowling, F.G.; Heussler, H.S.; McWhinney, A.; Dawson, P.A. Plasma and urinary sulfate determination in a cohort with autism. Biochem. Genet. 2013, 51, 147-153. [CrossRef] 
31. Lee, S.; Dawson, P.A.; Hewavitharana, A.K.; Shaw, P.N.; Markovich, D. Disruption of NaS1 sulfate transport function in mice leads to enhanced acetaminophen-induced hepatotoxicity. Hepatology 2006, 43, 1241-1247. [CrossRef]

32. Bowers, K.; Li, Q.; Bressler, J.; Avramopoulos, D.; Newschaffer, C.; Fallin, M.D. Glutathione pathway gene variation and risk of autism spectrum disorders. J. Neurodev. Disord. 2011, 3, 132-143. [CrossRef]

33. Hagiya, Y.; Kamata, S.; Mitsuoka, S.; Okada, N.; Yoshida, S.; Yamaoto, J.; Ohkubo, R.; Abiko, Y.; Yamada, H.; Akahoshi, N.; et al. Hemizygosity of transsulfuration genes confers increased vulnerability against acetaminophen-induced hepatotoxicity in mice. Toxicol. Appl. Pharmacol. 2015, 282, 195-206. [CrossRef] [PubMed]

34. Posadas, I.; Santos, P.; Blanco, A.; Muñoz-Fernández, M.; Ceña, V. Acetaminophen induces apoptosis in rat cortical neurons. PLoS ONE 2010, 5, e15360. [CrossRef] [PubMed]

35. Sullivan, J.E.; Farrar, H.C. The Section on Clinical Pharmacology and Therapeutics, Committee on Drugs. Fever and antipyretic use in children. Pediatrics 2011, 127, 580-587. [CrossRef] [PubMed]

36. Ip, E.J.; Patel, P.B.; Chi, J.J.; Shah-Manek, B.; Lau, B. What are pharmacists recommending for infant teething treatment? J. Am. Pharm. Assoc. 2018, 58, 79-83. [CrossRef]

37. Eden, L.M.; Lind, M.G.; Luthy, K.E.; Macintosh, J.L.B. Best Practice for Prevention of Vaccination Common Problems With Antipyretic/Analgesic Medications. J. Nurse Pract. 2017, 13, 462-467. [CrossRef]

38. Vernacchio, L.; Kelly, J.P.; Kaufman, D.W.; Mitchell, A.A. Medication use among children $<12$ years of age in the United States: Results from the Slone Survey. Pediatrics 2009, 124, 446-454. [CrossRef]

39. Bland, J.M.; Altman, D.G. Statistics notes. The odds ratio. BMJ 2000, 320, 1468. [CrossRef]

40. Pepe, M.S.; Janes, H.; Longton, G.; Leisenring, W.; Newcomb, P. Limitations of the odds ratio in gauging the performance of a diagnostic, prognostic, or screening marker. Am. J. Epidemiol. 2004, 159, 882-890. [CrossRef]

41. Nakayama, T.; Zaman, M.M.; Tanaka, H. Reporting of attributable and relative risks, 1966-97. Lancet 1998, 351, 1179. [CrossRef]

42. Walter, S.D. The estimation and interpretation of attributable risk in health research. Biometrics 1976, 32, 829-849. [CrossRef]

43. Bozdogan, H. Model selection and Akaike's Information Criterion (AIC): The general theory and its analytical extensions. Psychometrika 1986, 52, 345-370. [CrossRef]

44. Rockhill, B.; Newman, B.; Weinberg, C. Use and misuse of population attributable fractions. Am. J. Public Health 1998, 88, 15-19. [CrossRef] [PubMed]

45. Kleinbaum, D.G.; Kupper, L.L.; Morgenstern, H. Epidemiologic Research; Lifetime Learning Publications: Belmont, CA, USA, 1982.

46. Greenland, S.; Thomas, D.C. On the need for the rare disease assumption in case-control studies. Am. J. Epidemiol. 1982, 116, 547-553. [CrossRef] [PubMed]

47. Daniels, A.M.; Mandell, D.S. Explaining differences in age at autism spectrum disorder diagnosis: A critical review. Autism 2014, 18, 583-597. [CrossRef] [PubMed]

48. Infante-Rivard, C.; Jacques, L. Empirical study of parental recall bias. Am. J. Epidemiol. 2000, 152, 480-486. [CrossRef]

49. Vrijheid, M.; Armstrong, B.K.; Bédard, D.; Brown, J.; Deltour, I.; Iavarone, I.; Krewski, D.; Lagorio, S.; Moore, S.; Richardson, L.; et al. Recall bias in the assessment of exposure to mobile phones. J. Expo. Sci. Environ. Epidemiol. 2009, 19, 369-381. [CrossRef]

50. Mackenzie, S.G.; Lippman, A. An investigation of report bias in a case-control study of pregnancy outcome. Am. J. Epidemiol. 1989, 129, 65-75. [CrossRef]

51. Leon, A.C.; Heo, M. Sample Sizes Required to Detect Interactions between Two Binary Fixed-Effects in a Mixed-Effects Linear Regression Model. Comput. Stat. Data Anal. 2009, 53, 603-608. [CrossRef]

52. Jensen, J.F.; Gottschau, M.; Siersma, V.D.; Graungaard, A.H.; Holstein, B.E.; Knudsen, L.E. Association of maternal self-medication and over-the-counter analgesics for children. Pediatrics 2014, 133, e291-e298. [CrossRef]

53. Jensen, J.F.; Tønnesen, L.L.; Söderström, M.; Thorsen, H.; Siersma, V. Paracetamol for feverish children: Parental motives and experiences. Scand. J. Prim. Health Care 2010, 28, 115-120. [CrossRef]

54. Maiman, L.A.; Becker, M.H.; Katlic, A.W. Correlates of mothers' use of medications for their children. Soc. Sci. Med. 1986, 22, 41-51. [CrossRef] 
55. Baio, J.; Wiggins, L.; Christensen, D.L.; Frieden, T.R.; Jaffe, H.W.; Cono, J.; Richards, C.L.; Iademarco, M.F.; Moran, J.S.; Gasey, C.G.; et al. Prevalence of Autism Spectrum Disorder Among Children Aged 8 Years-Autism and Developmental Disabilities Monitoring Network, 11 Sites, United States, 2014. MMWR. Surveill. Summ. 2018, 67, 1-23. [CrossRef] [PubMed]

56. Rückinger, S.; von Kries, R.; Toschke, A.M. An illustration of and programs estimating attributable fractions in large scale surveys considering multiple risk factors. BMC Med. Res. Methodol. 2009, 9, 7. [CrossRef] [PubMed]

(C) 2020 by the authors. Licensee MDPI, Basel, Switzerland. This article is an open access article distributed under the terms and conditions of the Creative Commons Attribution (CC BY) license (http://creativecommons.org/licenses/by/4.0/). 